\title{
Impulsivity predicts treatment outcome in obese children
}

Citation for published version (APA):

Nederkoorn, C., Jansen, E. L. G. M., Mulkens, S., \& Jansen, A. T. M. (2007). Impulsivity predicts treatment outcome in obese children. Behaviour Research and Therapy, 45, 1071-1075. https://doi.org/10.1016/j.brat.2006.05.009

Document status and date:

Published: 01/01/2007

DOI:

10.1016/j.brat.2006.05.009

Document Version:

Publisher's PDF, also known as Version of record

Document license:

Taverne

Please check the document version of this publication:

- A submitted manuscript is the version of the article upon submission and before peer-review. There can be important differences between the submitted version and the official published version of record.

People interested in the research are advised to contact the author for the final version of the publication, or visit the DOI to the publisher's website.

- The final author version and the galley proof are versions of the publication after peer review.

- The final published version features the final layout of the paper including the volume, issue and page numbers.

Link to publication

\footnotetext{
General rights rights.

- You may freely distribute the URL identifying the publication in the public portal. please follow below link for the End User Agreement:

www.umlib.nl/taverne-license

Take down policy

If you believe that this document breaches copyright please contact us at:

repository@maastrichtuniversity.nl

providing details and we will investigate your claim.
}

Copyright and moral rights for the publications made accessible in the public portal are retained by the authors and/or other copyright owners and it is a condition of accessing publications that users recognise and abide by the legal requirements associated with these

- Users may download and print one copy of any publication from the public portal for the purpose of private study or research.

- You may not further distribute the material or use it for any profit-making activity or commercial gain

If the publication is distributed under the terms of Article $25 \mathrm{fa}$ of the Dutch Copyright Act, indicated by the "Taverne" license above, 


\title{
Shorter communication
}

\section{Impulsivity predicts treatment outcome in obese children}

\author{
Chantal Nederkoorn*, Esther Jansen, Sandra Mulkens, Anita Jansen \\ Department of Experimental Psychology, Maastricht University, Maastricht, The Netherlands
}

Received 16 January 2006; received in revised form 8 May 2006; accepted 19 May 2006

\begin{abstract}
Treatment for obesity is still running short, particularly on the long term. However, some people do take advantage of treatments and are able to retain their weight loss. What makes the difference between those who can keep their weight loss and those who cannot? One possible predictor of relapse in obesity treatment is impulsivity. Overall, obese people are found to be more impulsive than lean people, especially obese binge eaters. Intuitively, it would make sense that the most impulsive people are less able to keep control over eating behaviour. Therefore, impulsivity could serve as an obstacle for treatment. In the present study impulsivity was measured with a behavioural task (the stop signal task) in 26 obese children. Overweight of the children was measured before and after treatment and at 6 and 12 months follow ups. The results show that impulsivity was related to overweight at all moments: The most impulsive children were the most overweight ones; even after 12 months. Moreover, impulsivity predicted therapy success: the most impulsive children lost less weight. Impulsivity appears to contribute to the difference between succeeding or failing in attempts to lose weight. (C) 2006 Elsevier Ltd. All rights reserved.
\end{abstract}

Keywords: Impulsivity; Obesity; Treatment; Childhood

\section{Introduction}

Obesity is a growing problem over almost the entire world and much effort is invested nowadays in both prevention and treatment. However, the results of behavioural interventions are disappointing. Although reasonable effects are achieved at the short term, about 5 to 15\% reduction of Body Mass Index (BMI, $\mathrm{kg} / \mathrm{m}^{2}$ ), most people fail to stabilize their new weight. Reviews show that after 1-5 years, the majority of obese individuals returned to or exceeded their initial BMI (e.g. Garner \& Wooley, 1991; Jeffery et al., 2000; Wadden, Sternberg, Letizia, Stunkard \& Foster, 1989). The figures in children are more optimistic (Epstein, Valoski, Kalarchian, \& McCurley, 1995), which may have several causes: parental support, children being less set in their habits, children having more structured opportunities to exercise and sport and, last but not least, children growing whereas their body composition is still changing (Epstein et al., 1995). Epstein and colleagues reported that after 6 months of cognitive behavioural treatment, almost half of the children had an impressive outcome of at least $20 \%$ reduction in overweight, while after 10 years almost 30 percent retained this large

\footnotetext{
*Corresponding author. Department of Experimental Psychology, University Maastricht, P.O. Box 616, 6200 MD Maastricht, The Netherlands. Tel.: + 31433881925 ; fax: + 31433884196 .

E-mail address: c.nederkoorn@psychology.unimaas.nl (C. Nederkoorn).
} 
reduction. However, not all children were this successful and a large proportion (exact numbers are not revealed) had no reduction or even gained in overweight. As shown, the variability in weight loss after treatment is large. Some people can retain their weight loss, others just cannot. This means that some children apparently are able to make life-style changes and alter their eating and activity patterns, while others are not. But what makes the difference? This is an important question in order to improve therapy and let more obese children profit.

One possible predictor of relapse in obesity treatment is impulsivity. Overall, obese people are found to be more impulsive than lean people, especially obese binge eaters (Davis, Strachan, \& Berkson, 2004; Nederkoorn, Braet, Van Eijs., Tanghe, \& Jansen, in press; Rydén et al., 2003, 2004). Intuitively, it would make sense that the most impulsive people are less able to retain control over eating behaviour and are more inclined to give in to the temptation of tasty and high caloric food. Indeed, impulsivity has been found to predict drop out of therapy (Hjördis \& Gunnar, 1989) and success of therapy (Jönnson, Björvell, Levander, \& Rössner, 1986). In this latter study, several personality traits, which consitute a syndrome of ego weakness or impulsivity, predicted weight loss after 1 year. That is: the more impulsive participants lost less weight. Nederkoorn et al. (in press) found that in obese children impulsivity, measured during treatment, was related to weight loss up till that point: the more impulsive children lost less weight. Although these research findings are consistent, the support is still meagre and confirmation is needed.

In the current study, a behavioural measure of impulsivity, namely response inhibition as measured with the stop signal task (Logan, Schachar, \& Tannock, 1997) was obtained from 8-12-year-old obese children before treatment. BMI was measured before and after treatment, and at 6 and 12 months follow ups. It was predicted that the most impulsive children show the least weight reduction on the different time points.

\section{Method}

Twenty-six children (17 girls) participated in this study. Mean age was $9.3(\mathrm{SD}=1.2)$. The inclusion criteria were: having more than $120 \%$ overweight, following regular education and age between 8 and 12 years. According to the EDE, only two children had objective eating binges during the 28 days before the treatment (eating more than appropriate and sense of lack of control). The children all received a behavioural treatment for overweight, 8 weekly group sessions within 8-10 weeks. The parents received 3 parental group sessions (Mulkens, 2005). As part of another study, for 9 children (chosen randomly), the treatment was extended after posttreatment measurements with 8 additional sessions (with either a behavioural or cognitive content). Weight and length of the children was measured at 4 moments: before treatment (T1), 4 weeks after the 8 sessions behavioural treatment (T2), 6 months after treatment (T3) and 12 months after treatment (T4).

Impulsivity was measured individually at $\mathrm{T} 1$ with the stop signal task (for more details, see Logan et al, 1997). In this task, a go-signal is presented on a computer screen and participants must respond as fast as possible by pressing the left or right button. In $25 \%$ of the trials, an acoustic stop signal is presented $250 \mathrm{~ms}$ after the presentation of the go-signal, which means that the participants must inhibit their response. When the participant is able to inhibit, the stop signal is, subsequently, presented $50 \mathrm{~ms}$ later, making the task more difficult. If the participant is not able to inhibit, the stop signal is, subsequently, presented $50 \mathrm{~ms}$ earlier, making the task easier. By this tracking system, participants are able to inhibit in approximately $50 \%$ of the stop trials. The two dependant measures are mean stop signal reaction time and mean stop signal delay. The stop signal reaction time (SSRT) is calculated by subtracking the mean stop signal delay from the mean reaction time. A longer SSRT means that the participant takes longer to inhibit his/her response and hence has poorer response inhibition. Longer SSRTs are related to impulsivity and impulsivity disorders, like ADHD (Logan et al., 1997; Schachar, Tannock, Marriot, \& Logan, 1995) and SSRTs are found to differentiate between obese and normal weight children and between restrained and unrestrained eaters (Nederkoorn et al., in press; Nederkoorn, van Eijs, \& Jansen, 2004).

\section{Results}

The sample was heterogeneous concerning age and sex. Because mean BMI varies with age and is different for boys and girls, percentage overweight calculated for age and sex was used. Of the 26 children, one was 
Table 1

Pearson correlations between impulsivity, percentage overweight and changes in overweight. In addition, means and standard deviations (SD) of the variables are listed ${ }^{\mathrm{a}, \mathrm{b}}$

\begin{tabular}{lllr}
\hline & Impulsivity (SSRT) & \% overweight at T1 & Mean (SD) \\
\hline Impulsivity (SSRT) & & & $236.9(74.8)$ \\
$\%$ overweight T1 & $.49^{*}$ & & $151(18.8)$ \\
$\%$ overweight T2 & $.46^{*}$ & $.94^{* *}$ & $145(21.7)$ \\
$\%$ overweight T3 & $.50^{*}$ & $.96^{* *}$ & $147.9(22.4)$ \\
$\%$ overweight T4 & $.40^{*}$ & $.96^{* *}$ & .22 \\
Change in overweight T2-T1 & $.44^{*}$ & $.40^{*}$ & $146.6(21.8)$ \\
Change in overweight T3-T1 & $.39^{\#}$ & .30 & $3.1 \%(7.3)$ \\
Change in overweight T4-T1 & $.48^{*}$ & $4.7)$ & $4.4 \%(6.6)$ \\
\hline
\end{tabular}

$\mathrm{T} 1=$ before treatment, $\mathrm{T} 2=$ after treatment, $\mathrm{T} 3=6$ months follow up, T4 = 12 months follow up; $\# p<.06,{ }^{*} p<.05,{ }^{* *} p<.01$.

${ }^{\mathrm{a}}$ The same analyses were performed with the completers only. The main conclusions did not change. The therapy appeared more successful in treating obesity (changes in overweight were $8.2 \%, 3.3 \%$ and $5.6 \%$, respectively).

${ }^{\mathrm{b}}$ The same analyses were performed with duration of treatment (no additional treatment vs. 8 weeks additional treatment) as additional factor. The results did not change.

excluded from all analyses, because he did not perform the stop task rightly (never stopped to a stop signal). Of the 25 children, 19 eventually completed the treatment. At T2, two dropouts were measured, whereas one completer was not. At T3, only completers (19) were measured. At T4, 18 completers were measured. For missing values on percentage overweight, last known value was carried forward.

Treatment was successful in decreasing overweight: percentage overweight changed significantly over time $(F(3.22)=7.5, p<.01)$. Post hoc test showed that percentage overweight decreased significantly after treatment $(F(1,24)=16.3, p<.001)$, increased significant during follow up $1(F(1.24)=6.6, \mathrm{p}<.05)$ and decreased again, non-significantly, during follow up $2(F(1.24)=1.6$, n.s.). See Table 1 for means and SDs on all occasions. Decrease in overweight in the 9 children who followed additional treatment did not differ from the other children (at T3: $t(23)=.2, p=.8$; at T4: $t(23)=.1, p=.96)$.

The individual relations between impulsivity and percentage overweight at different time points were investigated using Pearson correlations (see Table 1). As hypothesized, impulsivity was significant related to overweight, before and after treatment, after 6 and 12 months: the most impulsive children had the highest percentage overweight on all occasions.

Next, the individual relationship between the impulsivity and changes in overweight at T2, T3 and T4 were tested with Pearson correlations (see Table 1). Results showed that impulsivity significantly predicted treatment success, as measured by change in percentage overweight, at T2 and T4 and marginally significant at T3. The most impulsive children lost least weight. Furthermore, overweight at $\mathrm{T} 1$ was also related to change in overweight at T3, but not at the other time points (see Table 1). Therefore, a multivariate linear regression model was used to test the unique effects of the risk factor impulsivity, controlling for overweight at T1 (see Table 2). It appeared that impulsivity, after controlling for overweight, predicted change in overweight, marginally significant at T2 and significant at T4, but not at T3. Overweight before treatment, however, did not predict change in overweight, after controlling for impulsivity.

\section{Discussion}

The results show that within a sample of obese children, impulsivity was related to percentage overweight: more impulsive children were more overweight. This was a stable relationship: impulsivity predicted percentage overweight at all time points, up to 12 months after treatment. Furthermore, impulsivity was also related to changes in overweight, both directly after treatment and during follow-ups: more impulsive children benefited less from the treatment than the less impulsive children. Overweight before treatment was also related to change in overweight, although only at time point T3, 6 months after treatment. It appeared that the most overweight children lost less overweight, although these children had the most room to improve. Apparently it was more difficult for them to lose weight. Entering both the impulsivity and the amount of 
Table 2

Univariate linear regression models examining the T1 risk factors impulsivity and percentage overweight and the subsequent changes in overweight at the different time points

\begin{tabular}{|c|c|c|c|c|c|c|}
\hline & $\beta$ & $95 \% \mathrm{CI}$ & $r$ & $R 2$ & $t$ & $p$ \\
\hline \multicolumn{7}{|c|}{ T1 risk factor } \\
\hline \multicolumn{7}{|c|}{ Change in overweight $\mathrm{T} 2-\mathrm{T} 1^{\mathrm{a}}$} \\
\hline$\%$ overweight & .087 & $-.079-.254$ & .22 & .049 & 1.18 & .29 \\
\hline SSRT & $.044^{*}$ & $.005-.082$ & .441 & .195 & 2.36 & .027 \\
\hline \multicolumn{7}{|c|}{ Change in overweight $\mathrm{T} 3-\mathrm{T} 1$} \\
\hline$\%$ overweight & $.142^{*}$ & $.022-.282$ & .400 & .16 & 4.4 & .047 \\
\hline SSRT & $.035^{\#}$ & $-.001-.07$ & .39 & .152 & 2.03 & .054 \\
\hline \multicolumn{7}{|c|}{ Change in overweight $\mathrm{T} 4-\mathrm{T} 1$} \\
\hline$\%$ overweight & .108 & $-.039-.254$ & .301 & .091 & 2.3 & .143 \\
\hline SSRT & $.043^{*}$ & $.009-.077$ & .477 & .227 & 2.6 & .016 \\
\hline
\end{tabular}

$\beta=$ unstandardized parameter estimate, $\mathrm{CI}=$ confidence interval.

${ }^{\mathrm{a}}$ The same analyses were performed with the completers only. The main conclusions did not change. SSRT predicted change in overweight from T2-T1 significantly, not at T3-T1, $p=.19$ and marginally significant at $\mathrm{T} 4-\mathrm{T} 1, p=.079$. Overweight at $\mathrm{T} 1$ precited change in overweight marginally significant at T3 $(p=.098)$.

overweight in a multivariate regression model showed that impulsivity did predict a reduction of overweight, both after treatment and 12 months after treatment, whereas overweight did not. This shows that it is not the overweight itself, but the impulsivity that was related to losing weight.

It should be noted that this study had a limited sample size. Attrition was substantial, which was the reason to perform intention to treat analyses, and one should only generalize with caution. Moreover, some children received additional treatment, after the second measurement, which could have caused additional variance in the data. Despite these limitations, the relation between impulsivity at the one hand and overweight and change in overweight at the other hand appeared robust. The results are consistent with previous findings, as discussed in the introduction. And although a larger population should be investigated for a prolonged period, the present study strengthens the likelihood that impulsivity plays an important role in obesity and treatment success.

The most plausible explanation for the effect of impulsivity on the lack of weight reduction is that their relationship is mediated by food intake: impulsive children seek immediate gratification and are less able to inhibit their responses and think these through. This might make impulsive children more vulnerable for the temptation of tasty food and it will be harder to stick to their diets. Earlier research showed that also in normal weight adults, impulsivity predicts food intake during a taste test (Guerrieri, Nederkoorn, \& Jansen, submitted). Moreover, obese children were found to overeat after exposure to tasty food, indicating that they are sensitive for the temptation of tasty food (Jansen et al., 2003). Only experimental research can reveal if impulsivity really causes overweight and obstructs loss of weight by triggering uncontrolled food intake.

If it turns out that impulsivity is indeed a main cause of excessive food intake, how can this information help in the battle against obesity? First, cognitive behavioural therapy should be directed more specific at reducing impulsive behaviour. Second, impulsivity probably does not stand alone, but interacts with our obesogenic environment. The omnipresence of tasty, high caloric highly accessible foods, are repeatedly linked to overweight and obesity (e.g. Levitsky, 2005). Changes in the environment might be an effective way to prevent obesity, especially for the people who are prone for immediate gratification and less able to control their impulses.

\section{References}

Davis, C., Strachan, S., \& Berkson, M. (2004). Sensitivity to reward: Implications for overeating and overweight. Appetite, 42, 131-138. Epstein, L. H., Valoski, A. M., Kalarchian, M. A., \& McCurley, J. (1995). Do children lose and maintain weight easier than adults: A comparison of child and parent weight changes from six months to ten years. Obesity Research, 3, 411-417. 
Garner, D. M., \& Wooley, S. C. (1991). Confronting the failure of behavioral and dietary treatments for obesity. Clinical Psychology Review, 11, 729-780.

Guerrieri, R., Nederkoorn, C., \& Jansen, A (submitted). How impulsiveness and variety influence food intake in a sample of healthy women.

Hjördis, B., \& Gunnar, E. (1989). Characteristics of drop-outs from a long-term behavioral treatment program for obesity. International Journal of Eating Disorders, 8, 363-368.

Jansen, A., Theunissen, N., Slechten, K., Nederkoorn, C., Boon, B., Mulkens, S., et al. (2003). Overweight children overeat after exposure to food cues. Eating Behaviors, 4, 197-209.

Jeffrey, R., Epstein, L. H., Wilson, G. T., Drewnowski, A., Stunkard, A. J., Wing, R. R., et al. (2000). Long-term maintenance of weight loss: Current status. Health Psychology, 19(Suppl. 1), 5-16.

Jönnson, B., Björvell, H., Levander, S., \& Rössner, S. (1986). Personality traits predicting weight loss outcome in obese patients. Acta Psyciatrica Scandinavia, 74, 384-387.

Levitsky, D. A. (2005). The non-regulation of food intake in humans: Hope for reversing the epidemic of obesity. Physiology and Behavior, $86,623-632$.

Logan, G. D., Schachar, R. J., \& Tannock, R. (1997). Impulsivity and inhibitory control. Psychological Science, 8, 60-64.

Mulkens, S. (2005). Prevention of obesity in adulthood: short term and six months follow-up effects of behavioural versus cognitive therapy for seriously overweight children. In Paper presented at the meeting of the British Feeding and Drinking Group annual meeting, Wageningen, the Netherlands.

Nederkoorn, C., Braet, C., Van Eijs., Tanghe, A., \& Jansen, A. (in press). Why obese children can not resist food: Impulsivity as a risk factor for obesity and an obstacle for treatment. Eating Behaviors.

Nederkoorn, C., Van Eijs, Y., \& Jansen, A. (2004). Restrained eaters act on impulse. Personality and Individual Differences, 37, $1651-1658$.

Rydén, A., Sullivan, M., Torgerson, J. S., Karlsson, J., Lindroos, A-K., \& Taft, C. (2003). Severe obesity and personality: A comparative controlled study of personality traits. International Journal of Obesity, 27, 1534-1540.

Rydén, A., Sullivan, M., Torgerson, J. S., Karlsson, J., Lindroos, A-K., \& Taft, C. (2004). A comparative controlled study of personality in severe obesity: a 2-y follow-up after intervention. International Journal of Obesity, 28, 1485-1493.

Schachar, R., Tannock, R., Marriot, M., \& Logan, G. (1995). Deficient inhibitory control in attention deficit hyperactivity disorder. Journal of Abnormal Child Psychology, 23, 411-437.

Wadden, T. A., Sternberg, J. A., Letizia, K. A., Stunkard, A. J., \& Foster, G. D. (1989). Treatment of obesity by very low calorie diet, behavior therapy, and their combination: A five-year perspective. International Journal of Obesity, 13(Suppl. 2 ), 39-46. 